\title{
Relationship between the general condition of acute lymphoblastic leukemia patients with remission rate and convulsion as an adverse effect chemotherapy
}

\author{
Rusdi Andid, Nurdiani, Bidasarai Lubis, Adi Sutjipto \\ Department of Child Health, Medical Faculty University of North Sumatera/H Adam Malik Hospital, Medan
}

\begin{abstract}
A retrospective study on the relationship between the general condition of acute lymphoblastic leukemia patients with remission rate and convulsion as an adverse effect of chemotherapy was conducted in leukemia patients of the hematology-oncology subdivision, Deparimenl of Child Health, Medical School, University of North Sumatra, Medan. Of 114 children with acute lymphoblastic leukemia, $81(71.05 \%)$ received chemotherapy, 31 patients among them was in good general condition. Remission rale of the 31 patients was $80.6 \%$ ( 25 children). Whereas in the remaining 50 patients, the remission rate among them was $84 \%$ ( 42 patients). There was no significant relationship between theirgeneral condition to the recurrence rate of Acute Lymphoblastic Leukemia patients who had been administered chemotherapy during induction phase. Convulsion was found in 2 cases, due to CNS leukemia. [Paedlatr Indones 2001;41:33-37]
\end{abstract}

Keywords: acute leukemia, remission rate, adverse reactions

Acute lymphoblastic leukemia (ALL) is a hemopoietic malignancy with predominantly pathologic lymphoblast. ${ }^{1}$ This disease may be curable; ${ }^{1,2}$ by modern chemotherapy and supportive care, $97-98 \%$ of patients achieve complete remission, ${ }^{3}$ which is defined as disappearance of clinical signs and symptoms of disease, normalization of peripheral blood value, and lymphoblast in bone marrow less than $5 \% .3 .5$ The increased remission rate is related by improvement in chemotherapy treatment, recognition of risk factors, and improvement of supportive care. ${ }^{6}$ Certain clinical appearances and laboratory findings corrclate to the prognosis of ALL patients. These include initial white blood cell count, age at diagnosis, gender,

Presented at 10th National Congress of Child Health, Bukit Tinggi, June 16th-20th. 1996. Correspondence: Rusdi Andid. MD, Department of Child Health, Medical School, University of North Sumatera - Adam Malik Hospital Jl. Bunga l-au No. 17, Medan. Indonesia. Ph. 061-830341/830405/6830143. Fax. 061-830255. cytogenesis, immuno-phenotype, FAB morphology, mediastinal mass, the presence of organomegaly, lymphadenopathy, hemoglobin level, race, platelet count, serum immunoglobulin, cyto-reduction rapidness, myeloid antigen findings in leukemic ccll. ${ }^{5}$ Based on these prognostic factors, ALL may be categorized into low risk and high risk groups, which are frequently used as the basis of ALL treatment. ${ }^{3.10} \mathrm{High}$ risk patients are generally treated more aggressively to achieve remission, while children in the standard or low risk group are treated with unequal effectiveness but less intensively to avoid adverse effect caused by chemotherapy. ${ }^{3.5}$ The combination of 3 cytostatic drugs is administered in the induction phase to achieve a good result for remission rate in ALL patients. ${ }^{3.69}$

Convulsion is one of the adverse effects that may occur during the remission of the induction phase in ALL patients. It may be due to intracerebral hemorrhage, leukemic cell infiltration into the central ner- 
vous system, cerebral edema, infection, electrolyte or metabolic disorders, and acute neurotoxic reaction caused by drugs." Certain cytostatic drugs such as vincristine and L-asparaginase are known to have neurotoxic effect and may lead to convulsion..$^{11-13}$ In this study we reviewed the remission rate of ALL patients with good general condition and bad general condition, and to find the incidence of convulsion as an adverse effect of chemotherapy during induction phase.

\section{Methods}

This study was conducted retrospectively by collecting data from medical records of ALL patients in Hematology-Oncology Division of the Department of Child Health, Medical School, University of North Sumatra, Medan, Indonesia, from January 1984 until December 1994 period.

From the data, $144 \mathrm{ALL}$ patients were obtained but 33 patients of them were excluded from the study because they did not receive cytostatic treatment. Eighty-one patients were eligible in the study and were classified into 2 groups, one group with those in good general condition and another group in bad general condition. Separation of the clinical condition was based on prognostic factors such as age of less than 2 years or older than 10 years, initial white blood cell count of less than $100.000 / \mu \mathrm{l}$, central nervous system leukemia, hepatosplenomegaly, lymphadenopathy, mediastinal mass. ${ }^{5}$ Bad general condition was concluded if there was one or more prognostic factor encountered. ${ }^{\mathrm{t}}$

The same treatment was given to all patients in both groups, i.e., the combination of 3 cytostatic drugs; prednisolone, vincristine, and L-asparaginase during induction for 4 weeks. Thereafter, all patients underwent thorough clinical examination, blood and bone marrow evaluation to define the occurrence of remission. The criteria of remission were disappearance of clinical signs and symptoms, normal peripheral blood values, and less than $5 \%$ of lymphoblast in bone marrow. ${ }^{3,4,5}$

All relevant data were collected in a special form. Statistical analysis was performed using the Chisquared test to find out the difference of remission rate between the two groups with the significance level of $95 \%(p<0.05)$.

\section{Results}

The prognostic related factors of ALL patients were age, initial white blood cell count, sex, FAB morphology, hepatosplenomegaly, lymphadenopathy and CNS leukemia (Table 1).

Fifty patients were male; 22 patients among them were in good general condition which 18 of them had remission. The other 28 patients were in bad general condition and 23 of them had remission. Thirty-one patients were female, 9 were in good general condition with 7 of them had remission, while 22 patients remained in bad general condition, while 12 among them had remission. Figure 1

Sixty-seven of 81 patients $(82.7 \%)$ experienced remission. In the good general condition group, 25 of 31 patients $(80.6 \%)$ had remission and in the bad general condition group 42 of 50 patients (84\%) also underwent remission. Statistical analysis showed that there was no significantly differences of remission rate in both groups. Table 2 . The remission rate in the age group of less than 2 years and older than 10 years was $83 \%$ and was $82 \%$ for the $2-10$ years age group. The difference of remission rates for both age groups was not significant (See Table 3).

\section{Discussion}

Eligible ALL patients in this study were given a combination of 3 cytostatic drugs, prednisone,

TABLE 1. PROGNOSTIC FACTORS OF ALL PATIENTS

\begin{tabular}{lc}
\hline Variable & Patient $\mathbf{n}=81$ \\
\hline Age & \\
$<2$ years & 9 \\
$>10$ years & 15 \\
Initial white biood cell count & \\
$<100.000 /$ ul & 68 \\
$>100.000 / u l$ & 13 \\
Sex Male & \\
Female & 50 \\
FAB morphology & 31 \\
L1 & \\
L2 & 56 \\
L3 & 24 \\
Hepatosplenomegaly & 1 \\
Lymphadenopathy & 40 \\
CNS leukemia & 2 \\
\hline
\end{tabular}




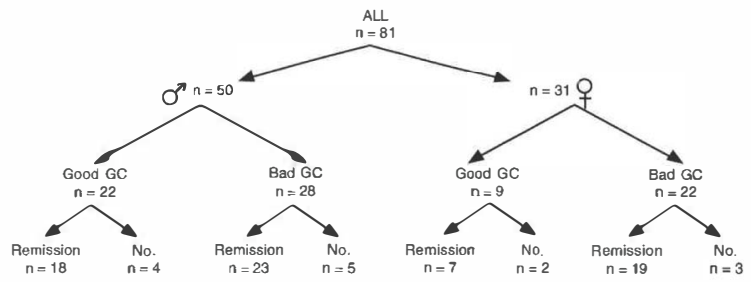

Figure 1. ALL patients who had remission

TABLE 2. COMPARISON OF REMISSION RATE BASED ON GENERAL CONDITION

\begin{tabular}{llllll}
\hline General condition & \multicolumn{4}{c}{ Remission } & Total \\
\cline { 2 - 5 } & + & $\%$ & - & $\%$ & \\
\hline Good & 25 & 80.6 & 6 & 19.4 & 31 \\
Bad & 42 & 84 & 8 & 16 & 50 \\
\hline$p>0.05$ & & & & &
\end{tabular}

TABLE 5. COMPARISON OF REMISSION RATES ACCORDING TO GENDER

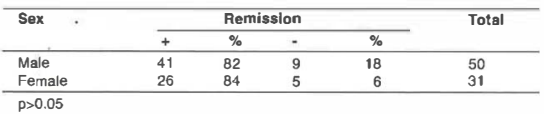

vincristine and $\mathrm{L}$-asparaginase, during remission of induction phase. Remission rate was achieved as much as $82.7 \%$. Remission rate of the group with good general condition was $80.6 \%$ while the group with bad general condition was $84 \%$. This remission rate was lower than that found in previous studies. Administration of the combination of the 3 cytostatic drugs prednisolone, vincristine and L-asparaginase during remission induction phase resulted in a remission rate > of $95 \%$ in ALL patients. ${ }^{3.69 .13}$

Abromowitch et al found $95 \%$ remission rate in ALL patients with standard risk. ${ }^{14}$ Gaynon and his co-workers reported even a higher percentage of remission rate, i.e., $99 \&$ in high risk ALL patients on
BFM regimen and $97 \%$ in those on the New York (NY) regimen. ${ }^{15}$ Furthermore, Miller et al reported that administration of the combination of the 3 cytostatic drugs prednisolone, vincristine and L-asparaginase during remission of induction phase for ALL patients in lower risk, 95\% remission rate was found without difference in ALL patients with higher risk; 95\% remission rate was found without difference in ALL patients in higher risk, i.e., $93 \% .^{16}$

Initial white blood cell count, age at diagnosis and sex are known as prognostic factors in ALL patients. ${ }^{7}$ The most important indicator is initial white blood cell count. ${ }^{13}$ Male patients have a worse prognosis than females. ${ }^{5,7.13}$ However, our data did not show 
that the male gender was a significant risk factor. It is suggested that another prognostic factor related to gender may be present to aggravate the prognosis in males. ${ }^{13}$

In this study, there was no significant difference in remission rate in the age group of $<2$ years $(82 \%)$. Leiper and Chessells J compared remission rate between the age group of $<2$ years and the age group of 2-14 years and found that the result was not difference $(94 \%$ in age group of $<2$ years and $97 \%$ in age group of 2-14 years). ${ }^{17}$ Although the differences of remission rate was not found in both age groups, the remission rate achieved in Leiper and Chessells' study was higher than this study.

In this study, remission ratc among different genders was not significantly different. Remission rate of ALL patients whose initial whitc blood cell count was $>100.000 / \mu \mathrm{l}(37 \%)$ was significantly lower than those with initial white blood cell count of $<100.000 / \mu \mathrm{l}$ (90\%) with $\mathrm{p}<0.05$, in this study. Equiquren et al reported that remission rate achicved in ALL patients with hyperleukocytosis (>100.00/ $\mathrm{\mu l}$ ) was $94 \%$ using a combination of 7 cytostatic drugs during inuction phase for 8 weeks. ${ }^{\text {is }}$ The remission rate reached in this study was much lower than study of Equiquren et al. It was due to our using of a combination of 3 cytostatic drugs for patients with hyperleucocytosis.

We did not find convulsion as an adverse effect of the administration of cytostatic drugs during induction phase. We found 2 children with convulsion due to CNS lcukemia. Pikko HMD et al observed 9 children with reversible convulsion as the adverse effect where intra cerebral vascularization. ${ }^{11}$ Johnston FL et al reported 4 cases with convulsion on the 5th and 6 th day after vincristine sulfate injection. In their cases, therc was no abnormality in lumbar puncture CT-scan or EEG. ${ }^{12}$

Priest JR and his co-workers reported that 13 of 18 children treated whitc vincristine, prednisone and L-asparaginase had deficiency of hemostatic plasma protein such as antithrombin, plasminogen and fibrinogen, which finally caused thrombus and intra cercbral hemorrhage. ${ }^{19}$

In conclusion, there was no significant difference of remission rate between ALL patients undergoing a combination 3 cytostatic drugs during the induction phase in good general condition and bad general condition. We did not find a significant difference mission rate based on age and gender, however, we found a significant difference of remission rates betwcen the two groups based on initial white blood cell count. The obtained remission rate in our series was much lower than that in the literature or other studies. There was no convulsion observed as the adverse effect of treatment during induction phase in all of ALL patients.

\section{References}

1. RSUP Sardjito. Treatment protocol of acutelymphoblastic leukemia. Presented on Course on Pediatrictric Oncology I, Semarang 1993.

2. Veerman AJP. Comprehensive protocol ALL 92. Amstendam: Dept. Pediatrics University Hospital, 1992; L-28.

3. Pui $\mathrm{CH}$ and Crist W. Biology and treatment of acute lymphoblastic leukemia. J Pediatr 1994;124:491-503.

4. Judith $\mathrm{O}$. Childhoodd acute lymphoblastic leukemia. In: Henderson ES, Lister TA, Greaves MF. Leukemia; 6th edition. Philadelphia: Saunders, 1994; 419-36.

5. Poplack DG. Acute lymphoblastic leukemia. In: Pizzo A, Poplack DG, eds. Principles and practised of pediatric Oncology. 2nd edition. Philadelphia: Lippincott, 1993;431-81.

6. Prince J. Management of acute leukemia in childhood. Presented on Course on Pediatric Oncology, Surabaya, 1996.

7. Champlin $\mathbf{R}$ and Gale RP. Acute lymphoblastic leukemia. Recent advances in Biology and Therapy. Blood 1989; 73:20-51-66.

8. Crist WM and Pui CM. The leukemias. In: Nelson WE, Behrman RE, Kliegman RM, eds. Nelson textbook of pediatrics, 15th ed. Philadelphia: Saunders 1996;1452-5.

9. Sallan E, Weinstein HJ. Childhood acute leukemia. In: Nathan DG, Oski FA, eds. Hematology of infancy and childhood; 3rd ed. Philadelphia: Saunders 1987;1028-63.

10. Pui $\mathrm{CH}$ and Dodge RK. Serum lactic dehydrohenase level has prognostic valuc in childhood acute lymphoblastic leukemia. Blood 1985; 66:778-82.

11. Pihko $\mathrm{H}$ and Tyui T. Treatment ischemic cerebral lessions during induction chemotherapy for acute lymphoblastic leukemia. J Pediarr 1993;123:718-24.

12. Johnson FL and Berstein ID. Seizure associated with vincristine sulfate therapy.J Pediatr 1973; 82:699-702.

13. Eden OB. Malignant disorders of lymphocytes. In: Lilley JS and Hann IM. Pediatric Hematology; 1st edition. Churchill Livingstones, 1992;329-56.

14. Abromowitch M, Ocks J, Pui CH, Fairclough D, Murphy SB, Riviera C. Efficacy of high dose metotrixate in childhood acute lymphoblastic leukemia. Analysis by contemporary risk classification. Blond 1988;71:866-9.

15. Gayuda PS, Bleyer WA et al. Intensive therapy for chil- 
dren with acute lymphoblastic leukemia and unfavourable presenting features. Lancet 1988; 921-4.

16. Miller DR, Lekin Set al. Prognostic factors and therapy in acute lymphoblastic leukemia of childhood; CCG-141. Cancer 1983;1041-9.

17. Lciper AD and Chessells. Acutc lymphoblastic leukemia under 2 years. Arch Dis Child 1986;61:1007-12.
18. Equiquren JM, Schell MJ et al. Complications and outcome in childhoed acute lymphoblastic leukemia with hypcrleukocytosis. Blocd 1992;79:871-5.

19. Priest JD, Ramsay NKC et al. A syndrome of thrombosis and hemorrhage complicating, L-asparaginase therapy for childhood acute lymphoblastic leukemia. J Pediatr 1982; 100:984-9. 